\title{
Multidisciplinary Care Improves Survival of Patients with Amyotrophic Lateral Sclerosis in the Unique Health System (SUS) in Brazil
}

Mirian Conceicao Moura ${ }^{1^{*}}$, Luiz Augusto Casulari ${ }^{2}$ and Maria Rita Carvalho Garbi Novaes ${ }^{3}$

${ }^{1}$ Hospital de Apoio de Brasilia, State Secretariat of Health of the Federal District, DF, Brazil

2 University Hospital of Brasilia, DF, Brazil

${ }^{3}$ School of Health Sciences, DF, and University of Brasilia, Brazil

*Corresponding author: Mirian Conceicao Moura, Hospital de Apoio de Brasilia, State Secretariat of Health of the Federal District, SAIN Qd. 04 Lote S/Número, CEP: 70071-125, Brasília-DF, Brazil, Tel: +556133254219; E-mail: mcmoura0812@yahoo.com.br

Received date: January 05, 2017; Accepted date: January 26, 2017; Published date: January 30, 2017

Copyright: (c) 2017 Moura MC, et al. This is an open-access article distributed under the terms of the Creative Commons Attribution License, which permits unrestricted use, distribution, and reproduction in any medium, provided the original author and source are credited.

\author{
Abstract \\ Objective: To determine the effectiveness of multi-professional palliative care in patients with amyotrophic lateral \\ sclerosis in Brazilian public health system.
}

Methods: Historic-control study before and after the Reference Center, with records and mortality data of 302 patients treated with riluzole between 2005 and 2015, were retrospectively evaluated and survival curves were analyzed.

Results: There were 181 men (59.9\%) and 121 women (40.1\%) with a diagnostic delay time of 28.1 months for spinal-onset and 20.1 months for bulbar-onset $(p=0.003)$ and a mean survival of $61.7 \pm 5.4$ months for spinal-onset and $38 \pm 3.5$ months for bulbar-onset $(p=0.01)$. Electromyography did not confirm the diagnosis in $55.6 \%$ of the suspected spinal-onset cases and $36.1 \%$ of the bulbar-onset. From 2005 to 2011 , mean survival was $33.6 \pm 2.4$ months, and after multidisciplinary care, $72.2 \pm 7.2$ months (log-rank: 0.0001).

Conclusion: Multidisciplinary care improves the survival of amyotrophic lateral sclerosis patients in the Unique Health System.

Keywords: Amyotrophic lateral sclerosis; Survival; Motor unit; Treatment; Multidisciplinary

\section{Introduction}

Amyotrophic lateral sclerosis (ALS) is an adult-onset neurodegenerative disease that is characterized by progressive loss of motor neurons in the brain, brain stem and spinal cord, thereby resulting in generalized weakness with muscle atrophy, dysphagia and respiratory distress, with a mean survival of 3-5 years [1]. In Brazil, the estimated incidence of ALS is 1-2 per 100,000 person-years [2].

Only one drug, riluzole, modifies disease progression in patients, but its effect is moderate, and it only extends survival by approximately 3 months [3]. In developed countries, evidence shows that multidisciplinary care has extended survival, decreased medical complications and improved the quality of life [4,5]. Patients attending multidisciplinary care also have fewer hospital admissions and shorter inpatient stays than those in general clinics $[4,6,7]$. This result is possibly due to the earlier diagnosis, increased use of riluzole and noninvasive ventilation (NIV), attention to nutrition and referral to palliative care services [4].

The concept of healthcare of the Unique Health System- Brazil (SUS) supports the principles of integrality and universality [8] and seeks the development of strategies that address the complexities inherent to healthcare. In this context, multidisciplinary teams have been described as the center of primary healthcare that ensure the integrality of healthcare [9]. However, a lack of evidence exists regarding the effectiveness of these teams in secondary and tertiary levels of care.

This work intends to show the importance of multi-professional teams in neuromuscular disease care and to describe the experience with ALS patients in the Brazilian public health system.

\section{Methods}

This retrospective, population-based and historic-control study was conducted using data from the medical records of patients treated before and after the Reference Center for Neuromuscular Diseases (CRDN), located in the Federal District, Brazil, from 2011 to 2015 and from riluzole-dispensing records between 2005 and 2015. The authors evaluated records from the CRDN through the TrakCare ${ }^{\bullet}$ software application (Intersystems, Brazil) from September 2011 to December 2015. All cases from the two sources described above were included as probable, and the ALS diagnosis was confirmed by a neurologist using the El Escorial and Awaji criteria [10,11] after exclusion of other diseases. Duplicated counts were averted using names, registry numbers and dates of birth. All patients used riluzole and underwent electromyography (EMG).

The database from the Mortality Information System of the Unified Health System (SIM/DATASUS) was reviewed for the same period, and the data were cross-referenced with those collected from the CRDN to confirm the dates of death of the patients. 
Page 2 of 6

The CRDN was created in September 2011 and is a multidisciplinary unit composed of medical neurologists, pulmonologists, physical therapists, occupational therapists, psychologists, nutritionists and speech therapists. The goals of the center include guiding patients and their families; reducing complications of immobility, dysphagia and respiratory failure; implementing the home ventilation program and giving support to professionals of the home care program (PID).

In every 3-4 months, patients and their families are seen by a neurologist with specialist expertise in ALS and a neuromuscular multidisciplinary team, including a physiotherapist, occupational therapist and a speech and swallow therapist and are given direct access to a pulmonologist, when indicated. A clinical assessment of respiratory function is conducted at each clinic visit using a same-day pulmonary function assessment by supine oximetry and spirometry, and if needed, NIV is initiated at home. The physiotherapy service has expertise in respiratory impairment, in addition to neurological disability, and provides onsite training in secretion management using techniques including breath stacking. The speech and swallow therapist addresses the management of swallowing to prevent aspiration pneumonia. The pharmacological management of secretions with anticholinergic medications (oral amitriptyline and topic atropine) is also offered. Adequate nutrition is addressed at every clinic and patients are weighed and encouraged to take dietary supplements. Patients with marked weight loss (greater than 10\%), increasing dysphagia, early respiratory impairment or evolving bulbar symptoms are reviewed by the multidisciplinary team. Decisions regarding intervention, including gastrostomy insertion, introduction of NIV and training in secretion management are made collectively.

In the study, we analyzed the following parameters: disease frequency, gender distribution, age at diagnosis, diagnostic delay time, duration of disease (survival), body mass index (BMI) and EMG findings to confirm the diagnosis.

Disease duration or survival time were defined as the time in months between the first symptom and death or tracheostomy. Diagnostic delay time was defined as the time in months between the onset of symptoms and the diagnosis.

The BMI at the onset of symptoms was calculated as weight $(\mathrm{kg}) /$ height $^{2}\left(\mathrm{~m}^{2}\right)$ [12].

The data were assessed again after exclusion of patients with more than 100 months of disease progression.

Data were recorded in Excel 2010, and statistical analyses were performed with SAS 9.3 and SPSS 19.0 applications. The chi-square test was used for categorical variables, and two-tailed Student's t-tests and $\chi^{2}$ tests were used for quantitative variables, comparing before and after CRDN. The survival functions for patients were estimated using the Kaplan-Meier method and compared using the log-rank test. The significance level was $\mathrm{p}<0.05$.

The study was approved by the Research Ethics Committee of Foundation of Teaching and Research in Health Sciences (FEPECS) in the Federal District, Brazil, under protocol No. 820.117/2014. The Ethics Committee waived the written consent form because the study consisted of the analysis of patient records (many patients were deceased) and secondary databases (mortality data).

\section{Results}

This retrospective population-based descriptive study evaluated all patients treated with riluzole from 2005 to 2015; 229 medical records and 73 riluzole-dispensing records were found, totaling 302 cases. The adjusted incidence rate for the population aged $>20$ years in the Federal District, according to the Instituto Brasileiro de Geografia e Estatistica (IBGE) census of 2010 [13], was 1.26 cases per 100,000 person-years in a population of $1,740,922$ inhabitants. The adjusted incidence rate for the population aged $>45$ years was 2.38 cases per 100,000 person-years in a population of 925,334 inhabitants.

The study sample consisted of 181 men (59.9\%) and 121 women (40.1\%), but this gender difference was not significant $(p=0.06)$. The frequency distribution is shown in Figure 1. The overall mean age of onset was $56.9 \pm 11.9$ years, with a range of 25 to 86 years. The average age of onset was $55.7 \pm 11.9$ years for men and $58.9 \pm 11.6$ years for women, with a significant difference in age between the sexes $(\mathrm{p}=0.02)$.

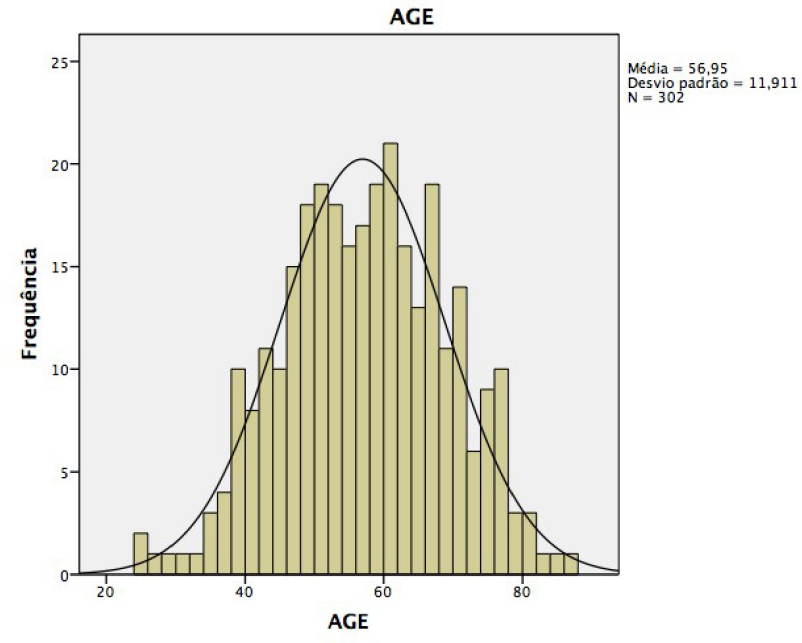

Figure 1: Histogram showing age distribution of patients with amyotrophic lateral sclerosis in Federal District, taking riluzole, 2005-2015.

A retrospective analysis of the records showed that at admission, 159 patients $(52.7 \%)$ were classified as Definite; 62 (20.5\%) were Probable; 60 (19.8\%) were Possible and $21(7 \%)$ were Suspect. A total of 240 patients $(79.5 \%)$ had spinal onset, and $62(20.5 \%)$ had bulbar onset. A family history of the disease was reported by $24(7.9 \%)$ patients and dementia, according to the Lund-Manchester Groups criteria 14, was observed in $15(5 \%)$ patients.

BMI at disease onset was calculated for 221 patients from their medical and drug-dispensing records and ranged from 16.5 to 39.6 $\mathrm{kg} / \mathrm{m}^{2}$, with an average of $24.1 \pm 4.1 \mathrm{~kg} / \mathrm{m}^{2}$. No significant difference was found between the sexes $(\mathrm{p}=0.6)$, but significantly lower values were found in the bulbar onset ALS group (Table 1).

In the same period, SIM/DATASUS data showed that 184 deaths occurred due to ALS in the region (102 men and 82 women), and all of these cases were also present in the CRDN database. The deaths occurred with similar frequency between 2005 and 2015, except in 2007, when nine deaths were reported. The highest frequency of deaths occurred in the age groups of 60-69 years and 70-79 years, accounting 
Citation: Moura MC, Casulari LA, Novaes MRCG (2017) Multidisciplinary Care Improves Survival of Patients with Amyotrophic Lateral Sclerosis in the Unique Health System (SUS) in Brazil. J Neurol Disord 5: 327. doi:10.4172/2329-6895.1000327

Page 3 of 6

for $59.8 \%$ of deaths. No deaths were reported in the $<30$ years age group. The mean age at death was $61.5 \pm 12.6$ years among men and $65.1 \pm$ in 12.2 years among women $(\mathrm{p}=0.06)$; the mean survival times were 45.6 months among men and 39.9 months among women, and the differences between the sexes were not significantly different $(\mathrm{p}=0.26)$.

EMG was performed on all patients, and the diagnosis was confirmed in 235 cases (77.1\%), as shown in Table 2. However, in 67 (22.9\%) cases initially classified as Suspect, the procedure did not confirm the diagnosis. Moreover, EMG did not confirm the diagnosis of the bulbar onset form in $22(36.1 \%)$ patients $(\mathrm{p}=0.011)$.

\begin{tabular}{|l|l|l|l|}
\hline Parameter & Spinal-Onset & Bulbar-Onset & P \\
\hline Age & $56.22 \pm 12.16$ & $59.79 \pm 10.52$ & 0.035 \\
\hline Delay time (months) & $28.13 \pm 30.72$ & $20.07 \pm 14.42$ & 0.003 \\
\hline Survival (months) & $46.71 \pm 46.59$ & $29.98 \pm 18.24$ & 0.0001 \\
\hline $\begin{array}{l}\text { Body mass index } \\
\text { (Kg/m })^{2}\end{array}$ & $24.4 \pm 4.4$ & $23.1 \pm 2.7$ & 0.014 \\
\hline $\begin{array}{l}\text { Upper motor neuron } \\
\text { signs }\end{array}$ & $174(72.5 \%)$ & $38(61.3 \%)$ & 0.085 \\
\hline Familial & $21(8.8 \%)$ & $3(4.8 \%)$ & 0.432 \\
\hline Caucasian & $55(88.7 \%)$ & $199(82.9 \%)$ & 0.66 \\
\hline Positive ENMGt & $196(81.3 \%)$ & $39(64 \%)$ & 0.011 \\
\hline Definite + probable ${ }^{\ddagger}$ & $189(78.7 \%)$ & $32(51.6 \%)$ & 0.02 \\
\hline Dementia & $8(3.4 \%)$ & $7(11.3 \%)$ & 0.003 \\
\hline
\end{tabular}

Table 1: Clinical profile of patients with amyotrophic lateral sclerosis in Federal District. 2005 to 2015. N=302. ${ }^{*}$ Delay time: onset of symptoms to diagnosis in months; $\mathrm{t}_{\mathrm{t}} \mathrm{ENMG}=$ Eletro-Neuromyography ${ }^{\ddagger}=\mathrm{El}$ Escorial criteria [10].

\begin{tabular}{|l|l|l|l|}
\hline Onset & Confirmatory (\%) & Non-Confirmatory (\%) & Total \\
\hline Bulbar & $39(63.9)$ & $22(36.1)$ & 61 \\
\hline Spinal & $196(81.3)$ & $45(18.7)$ & 241 \\
\hline Total & $235(77.1)$ & $67(22.9)$ & 302 \\
\hline
\end{tabular}

Table 2: Electromyography results in patients with amyotrophic lateral sclerosis in Federal District $(\mathrm{n}=302)$ according to El Escorial [10] and Awaji [11] Criteria. Period: 2005-2015.

The mean diagnostic delay was 28.1 months for spinal onset and 20.1 months for bulbar onset cases $(p=0.003)$. No significant differences were observed in the diagnostic delay time between the two groups before and after initiation of the CRDN.

In the second phase of the study, 12 patients (4\%) with more than 100 months of progression were considered outliers and excluded from the Kaplan Meier analysis, resulting in 290 patients included in the survival analysis (172 men and 118 women).

The results of the log-rank test, shown in Figure 2, indicate that the survival time of patients with spinal onset ALS was $61.7 \pm 5.4$ months, which was significantly longer than that for patients with bulbar onset ALS $(38 \pm 3.5$ months $(\mathrm{p}=0.01))$.

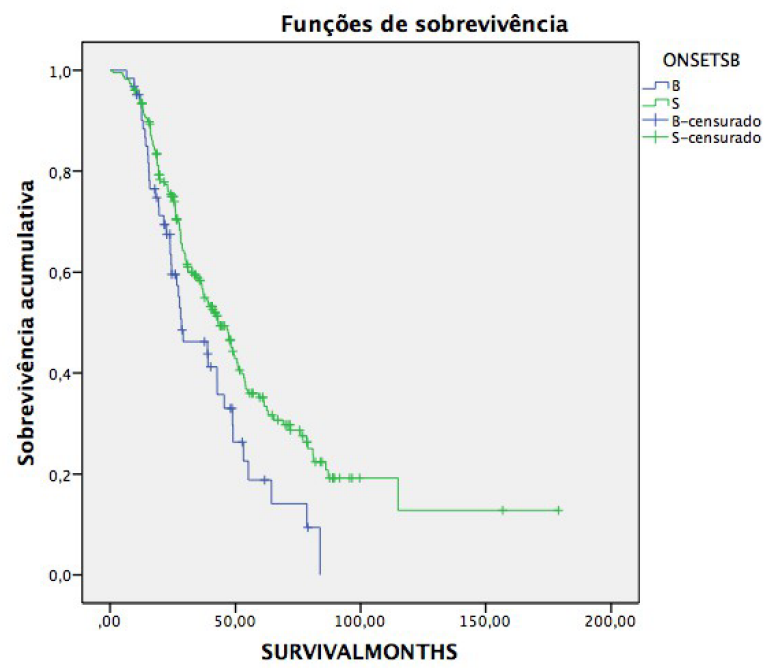

Figure 2: Kaplan Meier Curve ( $\mathrm{N}=290)$ comparing patients with amyotrophic lateral sclerosis and site of onset. Period: 2005-2015. (Log-rank: 0.0001. S: spinal-onset; B: Bulbar-onset).

The patients were divided into two groups, reflecting the periods from 2005 to 2011 (before CRDN) and from 2012 to 2015 (after CRDN), with 83 and 107 patients, respectively. Figure 3 shows that in the period from 2005 to 2011, the mean survival time was $33.6 \pm 2.4$ months, and in the period from 2012 to 2016 the mean survival time was $72.2 \pm 7.2$ months (log-rank: 0.0001).

The survival time was significantly longer in patients with spinal onset than in those with bulbar onset (2012-2015) when they were attended by the multidisciplinary care team at the CRDN, as shown in Table 3 and Figure 3 (Log-rank: 0.0001).

\begin{tabular}{|l|l|l|l|l|}
\hline Period & \multicolumn{2}{l|}{ Spinal-Onset } & \multicolumn{2}{l|}{ Bulbar-Onset } \\
\hline & Mean & Cl 95\% & Mean & CI 95\% \\
\hline $2005-2011$ & $33.8 \pm 2.7$ & $28.7-39$ & $32.7 \pm 5.7$ & $21.4-43.9$ \\
\hline $2012-2015$ & $78.7 \pm 8.3$ & $62.3-95$ & $41 \pm 4.7$ & $31.8-50.2$ \\
\hline
\end{tabular}

Table 3: Mean survival time in 290 patients with amyotrophic lateral sclerosis in Federal District before (2005-2011) and after (2012-2015) CRDN.

No accurate data could be found before 2012 regarding the use of NIV and gastrostomy tubes. In the 2012-2015 period, 18 (8.7\%) patients received a gastrostomy tube, 37 (18.4\%) received NIV and 16 (7.7\%) received invasive ventilation (IV), as shown in Table 4.

\begin{tabular}{|l|l|l|l|l|}
\hline \multicolumn{5}{|c|}{ Onset $n / N$} \\
\hline & Bulbar & Leg & Arm & Total (\%) \\
\hline NIV & $9 / 48$ & $14 / 78$ & $15 / 81$ & $38(18.4)$ \\
\hline
\end{tabular}




\begin{tabular}{|l|l|l|l|l|}
\hline IV & $9 / 48$ & $1 / 78$ & $6 / 81$ & $16(7.7)$ \\
\hline GTT & $12 / 48$ & $2 / 78$ & $4 / 81$ & $18(8.7)$ \\
\hline
\end{tabular}

support, percutaneous endoscopic gastrostomy (PEG) and palliative referral. This retrospective study shows that in the SUS, multiprofessional care can improve survival in patients with ALS, even for patients with bulbar onset who have a worse prognosis [20,21].

Table 4: Use of gastrostomy and mechanical ventilation in Amyotrophic Lateral Sclerosis at CRDN - Federal District $(\mathrm{N}=207)$ Period: 2012-2015. Abbreviations- n: patients that received intervention; N: Totality of Patients; NIV: Non-Invasive Ventilation; IV: Invasive Ventilation; GTT: Gastrostomy.
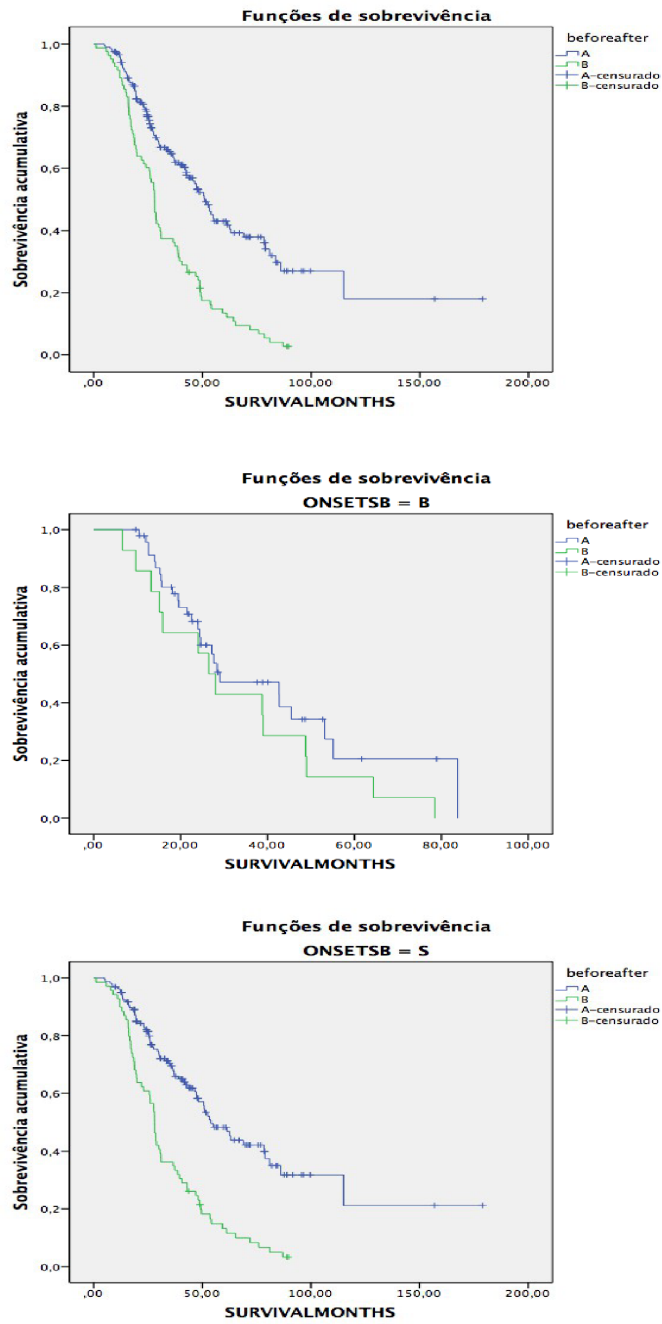

Figure 3: Kaplan Meier Curve $(\mathrm{N}=290)$ comparing survival of patients with spinal-onset amyotrophic lateral sclerosis before (B) in 2005-2011 and after (A) in 2012-2015 period. (3a: overall patients; $3 \mathrm{~b}$ : bulbar-onset patients; $3 \mathrm{c}$ : spinal-onset patients; Log-rank: 0.0001).

\section{Discussion}

Various studies have shown that a multidisciplinary approach to patients with ALS $[6,7,14-19]$ is associated with decreased hospital admissions and length of hospital stay and increased use of ventilator

Generally, the risk of death of bulbar onset ALS is 4.5-fold higher (RR: 4.56, $\mathrm{p}=0.0007)$ than that of spinal onset ALS [20,22]. One reason for this finding is malnutrition [12,23], and as shown in this study, the BMI was significantly lower in bulbar onset patients (Table 1). Additionally, it has been observed that these patients have an increased risk of aspiration and earlier respiratory distress [21].

Thus, studies with multidisciplinary units in the UK [24], Ireland [15] and Spain [18] have concluded that compared to ALS patients who were treated in neurology services, patients treated in multidisciplinary units have better survival, and patients whose symptoms began at the bulbar level especially benefited from multidisciplinary care. Nevertheless, the average one-year mortality rate is approximately $50 \%$ overall and $57 \%$ in bulbar cases [15].

Patients who benefit from a multidisciplinary approach also appear to receive more aids and appliances and have a higher quality of life [25].

Another point revealed by this study was demonstrated by the ALS diagnostic delay time. The mean diagnostic delay time (20.1 months) was significantly earlier in the bulbar onset group, but exceeded the time to diagnosis in other studies (10.1 months) [26]. The diagnosis of ALS requires signs of lower and upper motor neuron involvement, but the disease often resembles other common neurological conditions, such as spinal cord or nerve root syndromes. In this context, bulbar presentation is usually associated with a shorter time to diagnosis [26] because bulbar symptoms are not derived from spinal cord or root lesions, and likely, neurologists interpret progressive bulbar weakness as suggestive of ALS.

Nerve conduction and EMG studies are important tools for the identification of the extent of impairment of the lower motor neurons and neuronal loss [11] and to exclude other diagnoses. In the present study, the examination failed to confirm the disease in $55.6 \%$ of patients initially classified as suspicious and in $36.1 \%$ of cases of bulbar onset ALS, which reinforces the assumption that the clinical events should always be considered. Moreover, the low sensitivity of the procedure for bulbar onset ALS is supported by other studies [27,28]. A recent study in France, using the criteria of Awaji-shima, showed that the maximum sensitivity of EMG for bulbar onset ALS was $49.98 \%$ [27].

Thus, it is important to value the clinical evaluation and follow-up every three months, and tertiary specialized care centers play an important role in this aspect, especially in patients classified as Suspect [4-6,18]. Survival may be augmented by the increased use of riluzole, NIV and gastrostomy tube placement, but evidence shows that coordinated care independently improves the prognosis of ALS patients [24]. In the SUS, evidence also shows that multidisciplinary care reduces costs and the return visit frequency for patients with ALS [7].

The current European Federation of Neurological Societies guidelines recommend gastrostomy after weight loss of at least $10 \%$ of the premorbid weight [4]; therefore, it is also crucial that patients follow-up with specialized services. The effect of a gastrostomy on the quality of life of patients is controversial, but seems to be neutral, and the burden of caregiving activities is reduced after a gastrostomy [29]. 
Similar to other studies that showed that only [23] $6 \%$ to $30 \%$ of ALS patients use NIV [30,31], the frequency of NIV use was low in the present study (18\%), which is related to economic factors and to the long delay in diagnostic time. However, strong evidence exists that shows that NIV prolongs survival in ALS patients [4,30,32]. In a recent study [30], the median tracheostomy-free survival from symptom onset was 28 months in NIV-treated patients, compared to 15 months for untreated patients, and the benefit persisted after adjusting for age, gender, riluzole use and gastrostomy use. However, the only randomized controlled trial of NIV did not support this finding [33].

NIV is expensive and access is generally difficult [34]; however, given the important clinical benefits observed in ALS patients, determining the cost/benefit of increased access to NIV services should be a priority. Reductions in pulmonary function decline and respiratory complications have been observed in patients who undergo $[30,32]$, which suggests that future studies are needed to explore the optimal timing for NIV to optimize respiratory function, quality of life and survival.

Additionally, along with other studies, the present study confirms that the disease exhibits a later onset in women and for the bulbar onset variant [35]. It also exhibits an earlier onset in Latin American countries [36] and a predominance in the Caucasian phenotype [2,37], although these features do not impact survival rates.

\section{Conclusion}

In conclusion, in addition to reductions in costs and hospital admissions, care at specialized and multidisciplinary centers may improve survival in ALS, even in the public health system. This is probably due to early diagnosis, increased use of home ventilator support, gastrostomy, nutritional support and palliative referrals.

\section{References}

1. Hardiman O, Van Den Berg LH, Kiernan MC (2011) Clinical diagnosis and management of amyotrophic lateral sclerosis. Nat Rev Neurol 7: 639-649.

2. Moura MC, Casulari LA, Novaes MRCG (2016) Ethnic and demographic incidence of amyotrophic lateral sclerosis (ALS) in Brazil: A population based study. Amyotroph Lateral Scler Frontotemporal Degener 17: 275-281.

3. Miller RG, Mitchell JD, Lyon M, Moore DH (2012) Riluzole for amyotrophic lateral sclerosis (ALS)/motor neuron disease (MND). Cochrane Database Syst Rev 24: CD001447.

4. Andersen PM, Abrahams S, Borasio GD, De Carvalho M, Chio A, et al. (2012) EFNS guidelines on the clinical management of Amyotrophic lateral sclerosis (MALS) - Revised report of an EFNS task force. Eur J Neurol 19: 360-375.

5. Miller RG, Rosenberg JA, Gelinas DF, Mitsumoto H, Newman D, et al. (1999) Practice parameter: The care of the patient with amyotrophic lateral sclerosis (an evidence-based review). Neurology 22: 1104-1118.

6. Chiò A, Bottacchi E, Buffa C, Mutani R, Mora G, et al. (2006) Positive effects of tertiary centres for amyotrophic lateral sclerosis on outcome and use of hospital facilities. J Neurol Neurosurg Psychiatry 77: 948-950.

7. Moura MC, Novaes MR, Eduardo EJ, Zago YS, Feitas RD, et al. (2015) Impact of multidisciplinary care in amyotrophic lateral sclerosis hospitalizations in the public health system of Brazil. J Public Health Epidemiol 9: 317-323.

8. BRASIL (1990) Ministério da Saúde. Secretaria Nacional de Assistência à Saúde. ABC do SUS - Doutrinas e Princípios. Secr Nac Assist à Saúde.

9. Feriotti Mde L (2009) Equipe multiprofissional, transdisciplinaridade e saúde: desafios do nosso tempo. Vínculo 6: 179-190.
10. Ludolph A, Drory V, Hardiman O, Nakano I, Ravits J, et al. (2015) A revision of the el Escorial criteria - 2015. Amyotroph Lateral Scler Front Degener 16: 291-292.

11. Costa J, Swash M, De Carvalho M (2012) Awaji criteria for the diagnosis of amyotrophic lateral sclerosis:a systematic review. Arch Neurol 69: 1410-1416.

12. Shimizu T, Nagaoka U, Nakayama Y, Kawata A, Kugimoto C, et al. (2012) Reduction rate of body mass index predicts prognosis for survival in amyotrophic lateral sclerosis: A multicenter study in Japan. Amyotroph Lateral Scler 13: 363-366.

13. Instituto Brasileiro de Geografia e Estatística (IBGE) (2014) Censo Demográfico.

14. Miller BL, Ikonte C, Ponton M, Levy M, Boone K, et al. (1997) A study of the Lund-Manchester research criteria for frontotemporal dementia: Clinical and single-photon emission CT correlations. Neurology 48: 937-942.

15. Traynor BJ, Alexander M, Corr B, Frost E, Hardiman O (2003) Effect of a multidisciplinary amyotrophic lateral sclerosis (ALS) clinic on ALS survival: a population based study, 1996-2000. J Neurol Neurosurg Psychiatry 74: 1258-1261.

16. Williams UE, Philip-Ephraim EE, Oparah SK (2014) Multidisciplinary interventions in motor neuron disease. J Neurodegener Dis 2014: 435164.

17. Rooney J, Byrne S, Heverin M, Tobin K, Dick A, et al. (2015) A multidisciplinary clinic approach improves survival in ALS: a comparative study of ALS in Ireland and Northern Ireland. J Neurol Neurosurg Psychiatry 86: 496-501.

18. Rodríguez de Rivera FJ, Oreja Guevara C, Sanz Gallego I, San José Valiente B, Santiago Recuerda A, et al. (2011) Evolución de pacientes con esclerosis lateral amiotrófica atendidos en una unidad multidisciplinar. Neurologia 26: 455-460.

19. Turner MR, Kiernan MC (2015) The standard of care in amyotrophic lateral sclerosis: a centralised multidisciplinary clinic encounter sets a new benchmark for a uniquely challenging neurodegenerative disorder. J Neurol Neurosurg Psychiatry 86: 481-482.

20. Moura MC, Novaes MR, Eduardo EJ, Zago YS, Freitas Rdel N, et al. (2015) Prognostic factors in amyotrophic lateral sclerosis: a populationbased study. PLOS ONE 10: e0141500.

21. Turner MR, Scaber J, Goodfellow JA, Lord ME, Marsden R, et al. (2010) The diagnostic pathway and prognosis in bulbar-onset amyotrophic lateral sclerosis. J Neurol Sci 294: 81-85.

22. Forbes RB, Colville S, Cran GW, Swingler RJ (2004) Unexpected decline in survival from amyotrophic lateral sclerosis/motor neurone disease. J Neurol Neurosurg Psychiatry 75: 1753-1755.

23. Marin B, Desport JC, Kajeu P, Jesus P, Nicolaud B, et al. (2011) Alteration of nutritional status at diagnosis is a prognostic factor for survival of amyotrophic lateral sclerosis patients. J Neurol Neurosurg Psychiatry 82: 628-634.

24. Aridegbe T, Kandler R, Walters SJ, Walsh T, Shaw PJ, et al. (2013) The natural history of motor neuron disease: assessing the impact of specialist care. Amyotroph Lateral Scler Frontotemporal Degener 14: 13-19.

25. Miller RG, Anderson F, Brooks BR, Mitsumoto H, Bradley WG, et al. (2009) Outcomes research in amyotrophic lateral sclerosis: lessons learned from the amyotrophic lateral sclerosis clinical assessment, research, and education database. Ann Neurol 65 (Suppl 1): S24-S28.

26. Nzwalo H, De Abreu D, Swash M, Pinto S, De Carvalho M (2014) Delayed diagnosis in ALS: the problem continues. J Neurol Sci 343: 173-175.

27. Bresch S, Delmont E, Soriani MH, Desnuelle C (2014) Apport de l'electromyogramme dans le diagnostic precoce des SLA à début bulbaire: comparaison des criteres d'El Escorial, d'El Escorial modifies et d'Awaji. Rev Neurol (Paris) 170: 134-139.

28. Carvalho MD, Swash M (2009) Awaji diagnostic algorithm increases sensitivity of El Escorial criteria for ALS diagnosis. Amyotroph Lateral Scler 10: 53-57. 
Citation: Moura MC, Casulari LA, Novaes MRCG (2017) Multidisciplinary Care Improves Survival of Patients with Amyotrophic Lateral Sclerosis in the Unique Health System (SUS) in Brazil. J Neurol Disord 5: 327. doi:10.4172/2329-6895.1000327

Page 6 of 6

29. ProGas Study Group (2015) Gastrostomy in patients with amyotrophic lateral sclerosis (ProGas): a prospective cohort study. Lancet Neurol 14: 702-709.

30. Berlowitz DJ, Howard ME, Fiore JF Jr, Vander Hoorn S, O'Donoghue FJ, et al. (2016) Identifying who will benefit from non-invasive ventilation in amyotrophic lateral sclerosis/motor neurone disease in a clinical cohort. J Neurol Neurosurg Psychiatry 87: 280-286.

31. Vitacca M, Vianello A (2013) Respiratory outcomes of patients with amyotrophic lateral sclerosis: an Italian nationwide survey. Respir Care 58: 1433-1441.

32. Heritier Barras AC, Adler D, Iancu Ferfoglia R, Ricou B, Gasche Y, et al. (2013) Is tracheostomy still an option in amyotrophic lateral sclerosis? Reflections of a multidisciplinary work group. Swiss Med Wkly 143: w13830.

33. Bourke SC, Tomlinson M, Williams TL, Bullock RE, Shaw PJ, et al. (2006) Effects of non-invasive ventilation on survival and quality of life in patients with amyotrophic lateral sclerosis: a randomised controlled trial. Lancet Neurol 5: 140-147.

34. Garner DJ, Berlowitz DJ, Douglas J, Harkness N, Howard M, et al. (2013) Home mechanical ventilation in Australia and New Zealand. Eur Respir J 41: 39-45.

35. Dietrich-Neto F, Callegaro D, Dias-Tosta E, Silva HA, Ferraz ME, et al. (2000) Amyotrophic lateral sclerosis in Brazil: 1998 National Survey. Arq Neuropsiquiatr 58: 607-615.

36. Valenzuela D, Zitko P, Lillo P (2015) Amyotrophic lateral sclerosis mortality rates in Chile: A population based study (1994-2010). Amyotroph Lateral Scler Frontotemporal Degener 16: 372-377.

37. Zaldivar T, Gutierrez J, Lara G, Carbonara M, Logroscino G, et al. (2009) Reduced frequency of ALS in an ethnically mixed population: A population-based mortality study. Neurology 72: 1640-1645. 